\title{
An investigation of the online presence of UK universities on Instagram
}

\author{
Purpose - Rising tuition fees and a growing importance on league tables has meant that university branding \\ is becoming more of a necessity to attract prospective staff, students, and funding. Whilst university \\ websites are an important branding tool, academic institutions are also beginning to exploit social media. \\ Image-based social media services such as Instagram are particularly popular at the moment. It is therefore \\ logical for universities to have a presence on popular image-based social media services such as Instagram. \\ This paper investigates the online presence of UK universities on Instagram in an initial investigation of use. \\ Design/Methodology/Approach - This study utilizes webometric data collection, and content analysis \\ methodology.
}

Findings - The results indicate that at the time of data analysis for this investigation (Spring, 2015), UK universities had a limited presence on Instagram for general university accounts, with only 51 out of 128 institutions having an account. The most common types of images posted were humanizing $(31.0 \%)$, showcasing $(28.8 \%)$, and orienting (14.3\%). Orienting images were more likely to receive likes than other image types, and crowdsourcing images were more likely to receive comments.

Originality/Value - This paper gives a valuable insight into the image posting practices of UK universities on Instagram. The findings are of value to heads of marketing, online content creators, social media campaign managers, and anyone who is responsible for the marketing, branding, and promoting of a university's services.

Keywords - Social media; Instagram; images; universities; content analysis.

Paper Type - Research paper.

\section{Introduction}

With the increasing cost of tuition fees in UK higher education, and the high visibility of league tables, university branding has become a necessity (Stamp, 2004). Whilst the need to market academic institutions is controversial (Chapleo, 2011), substantial resources are being spent on branding institutions in order to attract staff, students, and funding (Rolfe, 2003). University websites are an important branding tool (Opoku, Abratt, and Pitt, 2006) and a relatively inexpensive way of showcasing key products and services (Kittle and Ciba, 1999). For prospective students, websites are critical for choosing universities and subjects (Rolfe, 2003). Whilst around 3 billion people have internet access, 2 billion are active social media users (Richards, 2016). Because of this huge audience, large organisations can benefit from participating on social media (McNely, 2012).

Academic institutions can exploit social media for marketing and branding, as well as for teaching and learning (Moran, Seaman \& Tinti-Kane, 2011; Salomon, 2013), and to engage with students (Hansen, Nowlan, \& Winter, 2012; Salomon, 2013). Although most US and UK universities have Twitter accounts (Parr, 2014), image-based social media services, such as Instagram, are particularly popular at the moment due to the proliferation of mobile phone photography (McNely, 2012; Rainie, Brenner, \& Purcell, 2012; Vong, 2012; Ibrahim, 2015); and the 'rise of the visual web' (comScore, 2013). It is therefore logical for universities to have a presence on popular image-based social media services such as Instagram.

This study is an initial investigation of official UK university Instagram accounts. It considers how UK universities use Instagram, how the site can help to engage with current and prospective students, and which factors indicate a successful Instagram presence.

\section{Literature review}

\section{Universities online}

An online presence for marketing and branding products and services is important for businesses (Kiang, Raghu \& Shang, 2000) and for UK universities (Roper \& Davies, 2007) due to the need to compete to attract staff, students, and funding (Stamp, 2004), and to present a corporate identity (Opoku, Abratt, and Pitt, 2006). The text and images that appear on a university website may often be the first and only institutional impression that a prospective student comes into contact with, and prospective students use websites to differentiate between offerings in a crowded higher education marketplace (Saichaie and Morphew, 2014). Despite this, there is little academic literature on university branding programmes (Chapelo, 2011). In an examination of 107 U.S. colleges and universities, Klassen and Stizman (2000) found that while some colleges and universities have built potentially useful web sites, many are failing to use the web effectively. Social media is now part of an organization's online presence, with most US and UK universities using Twitter (Parr, 2014). However, most of the literature that investigates social media within a university setting 
does so from a teaching and learning perspective (e.g., Moran, Seaman \& Tinti-Kane, 2011; Salomon, 2013) rather than investigating its use for marketing.

\section{The emergence of Instagram}

Social media services, 'employ mobile and web-based technologies to create highly interactive platforms via which individuals and communities share, co-create, discuss, and modify user-generated content' (Kietzmann et al. 2011, p.241). Social media has evolved over time from text-intensive services such as blogs and wikis, to more succinct message-based services such as microblogs (e.g., Twitter), and social networking sites (e.g., Facebook), and multi media services, such as YouTube and Tumblr. The current forerunners in social media are now image-based services, such as Instagram and Pinterest, and imagebased mobile messaging applications such as Snapchat. One of the main reasons for this shift to imagebased services has been the emergence of smartphone photography (McNely, 2012; Rainie, Brenner, \& Purcell, 2012; Vong, 2012; Ibrahim, 2015), coupled with the adoption of dedicated smartphone applications (apps), which have simplified the sharing of images with friends, family, and the world at large. Research by Van House and Davis (2005) in particular has found that cameraphone images are taken with very social intentions, including creating and maintaining social relationships, constructing personal and group memories, self-presentation, and self-expression. A large scale systematic study of image posting on Twitter in the UK and USA suggests that individual users are creative in terms of the types of images posted and often edit or transform images as well as posting screenshots of their smartphones (Thelwall et al., 2016). Although no study has been conducted on Instagram, it seems likely that the same will hold true.

Images are 'far more engaging than text alone' (Abbott et al., 2013), and engagement on Instagram may be 10 times greater than on other social media services (Moritz, 2012). Here, greater engagement means deeper, more meaningful, and sustainable interactions (Economist Intelligence Unit, 2007). The active user base of Instagram has surpassed that of Twitter, reaching 400 million users by 2015 (Instagram, 2015), compared to Twitter's 316 million active users (Kharpal, 2015), and Snapchat's 100 million active users (Tweney, 2015). These users share 80 million images per day on Instagram (Instagram, 2015). Instagram was originally released in October 2010 as an iPhone only service (BBC, 2012), allowing users to take pictures, apply filters, and share their images on Instagram or through other social networking services like Facebook and Twitter. In April 2012 the service was released on the Android platform and was acquired by Facebook for approximately $\$ 1$ billion (BBC, 2012). However, whilst public Instagram accounts can be viewed online, the posting of images to Instagram still remains a mobile only function.

\section{Types of images posted to Instagram}

Content analysis methodology has been used to gain insights into the types of images that are posted to Instagram. Using human coders, Hu, Manikonda and Kambhampati (2014) identified eight different types of Instagram image (Friends; Food; Gadgets; Captioned photos; Pets; Activities; Selfies; and Fashion). The Selfies and Friends categories were found to be the most common, accounting for $24.2 \%$ and $22.4 \%$ respectively of the 1,000 images in their sample (these images belonged to 50 random users, with 20 images each).

Guidry et al. (2014) investigated more than 700 Instagram images that contained negative content relating to the 10 largest fast food companies in the world. Posts were analysed for tonality, topic, negative emotion, and origin, with the intention of investigating Instagram as a new emerging crisis information form. Customers of the companies tended to post negative content about service issues rather than issues relating to the food itself, whereas employees of the companies tended to post negative content about their work environment.

McNely (2012) analysed Instagram images from a news organisation, a non-profit organisation, and a retailer using a qualitative coding scheme. The news organisation prominently posted images that included landmarks and artifacts related to newsworthy items (orienting images). The non-profit organization (providing sustainable solutions for hunger and poverty) posted images that predominantly related to both orienting artifacts and landmarks (orienting images), as well as images that placed the organisation in 'physical spaces where their work is carried out and needed' (placemaking images). The retailer (an online business specializing in vintage and vintage-inspired clothing and accessories) posted images that predominantly humanized the organisation. Employees of the organisation visually and materially modelled the organisational ethos, 'wearing fashionable couture, hairstyles, and accessories in stylized ways' and also portraying a fun work environment (humanizing images). None of these rich case studies directly relate to universities however. 


\section{How 'success' is measured on Instagram}

User accounts on Instagram can be either public or private. Images in private accounts are only viewable by users who have been approved to see them, whereas the images in public accounts can be viewed by anyone. Users can also choose to 'follow' other accounts (subject to approval in the case of private accounts). Following an account means that all of the images from the user that is being followed will be displayed in the feed of the person who is following the account. Instagram has an asymmetric network, which means that, 'if user $A$ follows $B, B$ need not follow $A$ back' (Hu, Manikonda, \& Kambhampati, 2014). The number of followers of an account is an indication of how successful it is, and the relationship between how many followers an account has and how many accounts they themselves follow can give an indication of how reciprocal an account is in engaging with its followers. Of course both metrics can be manipulated and followers can include spam accounts.

Another way that users on Instagram can interact with each other is through likes and comments posted to an image. Users can add comments to images on Instagram, and such comments may be positive or negative. Likes and comments reflect the popularity of a post (Vries, Gensler, \& Leeflang, 2012) and counting the number of positive comments and 'likes' that an image receives is one way to estimate the 'success' of an Instagram image. One of the organisations included in McNely's (2012) investigation found that posting images frequently generated many comments from its followers. Nevertheless, following more users does not automatically result in more likes for images posted by an account, although specialist accounts tend to have their images liked more often (Jang, Han, and Lee, 2015). Instagram posts about 'events' or 'promotion' tend to generate most involvement from followers (Coelho, Oliveira, \& Almeida, 2016). Users tend to 'like' images on Instagram more than comment on them, with 1.7 million media posts obtained in one investigation receiving 1.2 billion 'likes' but only 41 million comments (Ferrara, Interdonato, \& Tagarelli, 2014). This huge disparity is due to commenting requiring more cognitive effort than 'liking' (Ferrara, Interdonato, \& Tagarelli, 2014). Of course, the number of 'likes' or 'comments' on an image is not an accurate measure of its success in terms of its intended goal and other methods are needed for this (e.g., assessing whether library photos lead to more library users: Abbott et al., 2013).

University libraries can be active users of Instagram. Los Angeles Powell Library at the University of California attempts to engage their followers by: re-posting interesting students' images; by 'liking' images that are geotagged within the library or include certain hashtags;, by posting on student-related topics; by incorporating curriculum-related content; by only posting good quality images; and by posting only one image per day so as to not clutter up their followers' feeds. This strategy seems to have allowed the library to connect better with students on Instagram than on any other social networking service (Salomon, 2013). Part of the reason for Instagram's success in this case may be that it reaches a 'young, urban, and diverse demographic', that closely reflects the hosting university's undergraduate population (Salomon, 2013).

A study of fast food companies on Instagram found that they had very little engagement with their followers and tended to ignore negative comments directed at them (Guidry et al., 2014). During the two week sampling period, only 7 out of the 10 companies investigated were active on Instagram, and they rarely used it overall, with only 49 posts between them. There seems to be a need for public relation professionals to take Instagram more seriously, in this industry at least (Guidry et al., 2014, p. 2).

Other research on Instagram has produced visualizations of user photos in order to gain social, cultural, and political insights into activities and particular locations (Hochman and Manovich, 2013).

\section{Research questions}

This paper investigates how UK universities are using the image-based social media service Instagram. More specifically, it addresses the following research questions:

RQ 1 - Which types of images are posted most frequently by universities on Instagram?

$R Q$ 2- Can a successful presence on Instagram be predicted by the types of images posted? - Is there a relationship between the type of image posted and the number of likes or comments that it receives?

RQ 3 - Can a successful presence on Instagram be predicted by other quantitative measures of Instagram behaviour?

- Is there a relationship between the number of accounts that an institution follows and the number of followers that the institution has?

- Is there a relationship between the number of images that an institution posts and the number of followers that the institution has? 


\section{Methodology \\ Identifying universities to investigate}

Using a table published by the Times Higher Education Supplement that listed UK academic institutions according to their intensity-weighted GPA ranking in the 2014 Research Excellence Framework (REF), a list of 128 UK academic institutions was obtained that submitted more than one unit of assessment in REF 2014. The Times Higher Education Supplement was used as a contemporary source of information that includes up-to-date institutional names. The 128 institutions on this list were then investigated for their use of image-based social media services.

The homepage of each university website was checked for a link to a general (university-wide) Instagram account. When no link was found, the 'contact' page was then checked, and if present, the, 'social media'/'social media directory' page link on the university homepage. From the 128 institutions, 51 general Instagram accounts were identified. In some cases where no Instagram account was found, social media accounts may have been listed on other pages of a university's website. Such accounts were presumably not considered important enough by the university to publicize and and were ignored. An exhaustive search for such pages would have been impractical, given the size of university websites. For universities with multiple Instagram accounts, only general (university-wide) accounts were included and accounts for alumni, the library, and departments were ignored. Such accounts may have different goals and would therefore not be directly comparable. For example, the engineering department would presumably post engineeringrelated images and the library would post library-related images (e.g., Salomon, 2013).

\section{Data collection}

Data was collected via Instagram's Application Programming Interface (API) in February 2015 from each of the 51 universities for which a general Instagram account had been found. First basic information about the university account was collected: total number of images and videos posted;,profile text description; number of followers; and number of accounts followed. Next, for all public images posted by the account, the following information was extracted: URL; date posted; number of comments received; and number of likes received. Although all images analysed were publicly available, to ensure ethical treatment of them, no information of a personal nature or that could identify an individual was shared.

For each university, a random sample of 20 images was then selected for the final sample using Excel's random number generator feature. Selecting random images ensured that the final sample of images was not biased in terms of only including images that had recently been posted, or sets of similar images that had perhaps been posted in close succession to one another that may have all related to the same subject. The final sample consisted of 1,020 images.

Although it would have been possible to conduct a case study on a small number of universities, and this would have allowed for richer insights into the universities selected, it would be difficult to generalise to other universities.

\section{Image content analysis}

Content analysis was adopted to answer RQ 1. Content analysis involves using one or more human judges to categorise objects based upon their subjective opinions into a set of classes that are relevant to the research goals, and following a written scheme (Krippendorf, 2004). Such an analysis is able to characterise the properties of a large set of images, and is an alternative strategy to more in-depth investigations of a small set of images (Rose, 2012). A content analysis scheme was developed for analysing the publicly available images posted on university Instagram accounts based on the coding scheme developed by McNely (2012) for Instagram use in organizations (see Table 1).

McNely's (2012) scheme has three analytic axes: 1 . The content of the photo; 2 . The photo description and any accompanying tags; 3 . Direct interaction with followers via photo comments. An investigation of university-related Flickr images also argued that that accompanying text and tags need to be taken into consideration when classifying an image (Angus, Stuart, \& Thelwall, 2010). Thus, in this investigation, image descriptions and tags were examined in order to give context to the images. This is especially important for classifying the purpose of an image.

McNely's (2012) six coding categories closely aligned with the potential purposes of university image posts on Instagram, and the category descriptions were re-worded to fine-tune their relevance for this investigation. The Instagram accounts in McNely's (2012) study are likely to be predominantly external to the organizations themselves. In contrast, university accounts are likely to be followed both by internal (e.g., current staff and students) and external (e.g., prospective students, alumni etc.) people. This was taken into account in the fine-tuning of the scheme. 


\section{Reliability of the content analysis scheme}

In order to test the reliability of the content analysis results, a second classifier was used to classify $10 \%$ of the sample of 1,020 images. Using Krippendorf's alpha, interrater reliability was measured for each of the six content analysis categories. The initial agreement rate between the two classifiers was not high enough to ensure that the content analysis scheme was reliable (Table 1 column 1). The primary researcher and second classifier then met to discuss the reasons that potentially caused the disagreements, and based on this discussion, the content analysis scheme was reworded to eliminate the ambiguities identified (Krippendorf, 2004). The primary researcher and second classifier then independently classified a further $10 \%$ of the sample, and Krippendorf's alpha was recalculated for the six content analysis categories (see Table 1, column 2). Alpha score between .667 and .8 are suitable for drawing tentative conclusions (Krippendorf, 2004), and since the recalculated alpha scores were all above .667, the content analysis scheme is acceptably reliable (see Table 2 for the final content analysis scheme).

Table 1. Interrater reliability for the content analysis scheme

\begin{tabular}{|l|l|l|}
\hline & Krippendorf's alpha (1st attempt) & Krippendorf's alpha (2nd attempt) \\
\hline 1 - Orienting & 0.32 & 0.78 \\
\hline 2 - Humanizing & 0.49 & 0.74 \\
\hline 3 - Interacting & 0.38 & 0.79 \\
\hline 4 - Placemaking & 0.31 & 0.87 \\
\hline 5 - Showcasing & 0.46 & 0.7 \\
\hline 6 - Crowdsourcing & 0.23 & 0.69 \\
\hline
\end{tabular}

Table 2. Content analysis scheme for images posted on university Instagram accounts

\begin{tabular}{|l|l|c|}
\hline Category & Description & 1 \\
\hline Orienting & $\begin{array}{l}\text { The primary focus of the image is of specific and unique university (and university } \\
\text { associated) locations, landmarks, or artifacts (e.g., buildings/public } \\
\text { areas/statues/university affiliated objects). If the image is accompanied by a photo } \\
\text { description or tag(s) that specifically denotes the exact name of a building, statue, or } \\
\text { location etc. then this image should be classified as orienting. } \\
\text { However, the inclusion of a geotag location title does not necessarily mean that an } \\
\text { image should be classified as orienting. }\end{array}$ & $\begin{array}{l}\text { The primary focus of the photo is of things that add more of a human character or } \\
\text { element of warmth/humour/or amusement to the university's identity (e.g., close-up } \\
\text { people shots featuring staff, students, or people affiliated with the university - } \\
\text { contextual items within the photo itself, as well as photo description and tags will } \\
\text { allow the classifier/viewer to be able to make a judgement regarding whether any } \\
\text { people contained within the photo are affiliated with the university). Also photos that } \\
\text { contain food, pets, university mascots, or people playing music as part of normal } \\
\text { everyday university occurrences. Nature images may also be classified as } \\
\text { humanizing if they are not accompanied with a specific location title or tag(s). }\end{array}$ \\
\hline Humanizing & $\begin{array}{l}\text { This category also contains historical photos and posts that specifically want to } \\
\text { convey happy/positive sentiments. }\end{array}$ & 2 \\
\hline Interacting & $\begin{array}{l}\text { The primary focus of the image is centered around people interacting at university } \\
\text { (and university associated) events rather than people merely posing for staged } \\
\text { photographs (e.g., an image of students participating in the freshers fair/ an image } \\
\text { of a group of people being shown around at a university open day/ or an image of } \\
\text { people actively participating in a sporting event). }\end{array}$ & 3 \\
\hline $\begin{array}{l}\text { The primary focus of the image is concerned with the university 'placing' their } \\
\text { identity within locations or events (e.g., generic photos of the inside of } \\
\text { buildings/lecture theatres/student halls, or generic images of graduation ceremonies }\end{array}$ & 4 \\
\hline
\end{tabular}




\begin{tabular}{|l|l|l|}
\hline Showcasing & $\begin{array}{l}\text { where no one specific person is the focus of the image). } \\
\text { Placemaking images will not be accompanied by specific descriptions or tags } \\
\text { indicating the exact name of any buildings etc. contained within the image. }\end{array}$ & $\begin{array}{l}\text { The primary focus of the image is to: display products or goods for sale (e.g., } \\
\text { university sweatshirts or merchandise); showcasing students' or staff work (e.g., } \\
\text { close-up shots of artwork at an exhibition or other student work at a university event. } \\
\text { Or if the image has been posted to display the 'winning image' in a photo } \\
\text { competition of some sort); if the image seeks to promote university specific services } \\
\text { or advertise upcoming events (e.g., a photo of a poster advertising an upcoming } \\
\text { public lecture, fundraising event, or charity ball); or if the image seeks to promote } \\
\text { generic student activities and events (e.g., students taking part in a course field trip, } \\
\text { or team squad lineup images). Promotional videos may also be classified as } \\
\text { showcasing. }\end{array}$ \\
\hline Crowdsourcing & $\begin{array}{l}\text { The primary purpose of the image is that it has been posted with the intention of } \\
\text { generating feedback, interaction, and engagement with viewers/followers (e.g., an } \\
\text { image of a text-based message requesting followers to share and tag images of a } \\
\text { particular place/thing, or an image of a new logo design asking students for their } \\
\text { thoughts and feedback). } \\
\text { If the content of the image itself fits within a different classification category but the } \\
\text { image is accompanied by text that explicitly asks for viewer feedback then this } \\
\text { image should be classified as crowdsourcing. }\end{array}$ & 5 \\
\hline
\end{tabular}

\section{Inferential statistics}

In order to answer $R Q 2$ and $R Q$ 3, a multinominal logistic regression, and a Spearman's correlation test were used, respectively.

\section{Results}

A total of 11,398 images were collected via the API for the 51 universities identified in this investigation. The mean number of images for each university account was 223 , with an average of 1,455 followers each and with the accounts following an average of 90 others. Most universities had been a member of Instagram since 2013, and for an average of 585 days (approximately 20 months). Figures $1-4$ show the distribution of number of images, number of followers, number of accounts followed, and number of days for which universities had been a member of Instagram, in rank order. In all cases, a few universities had much higher values than the others.

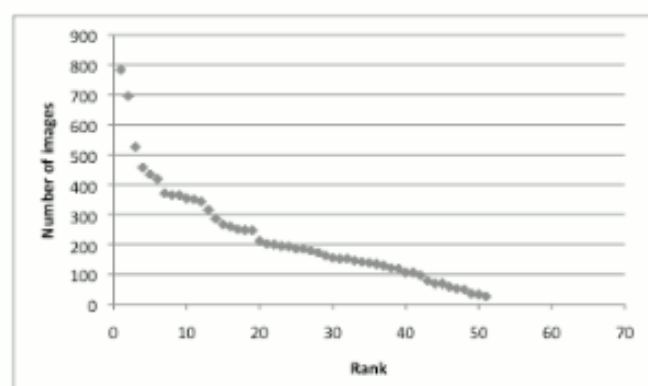

Figure 1. Number of images

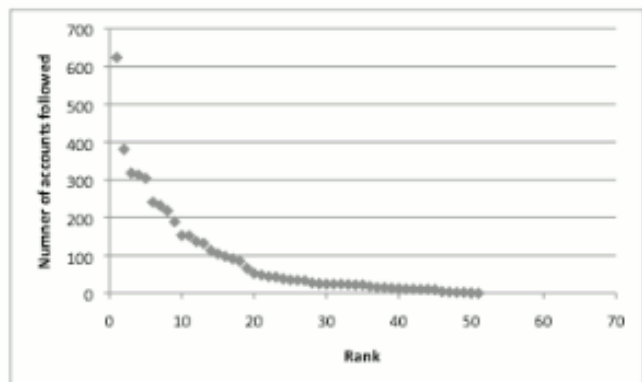

Figure 3. Number of accounts followed

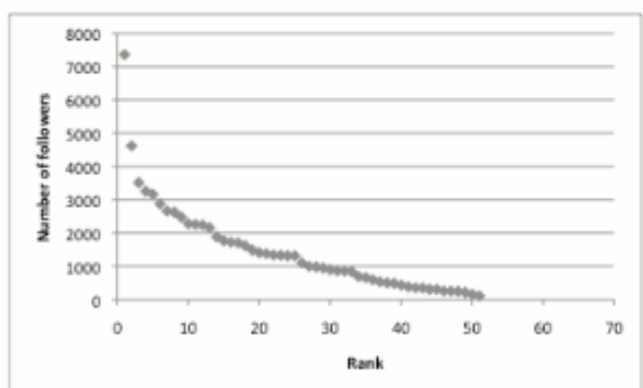

Figure 2. Number of followers

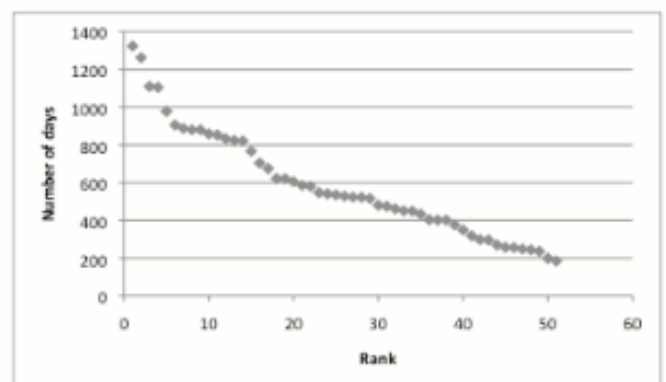

Figure 4. Number of days a member of Instagram 


\section{Image content analysis}

From the content analysis of the random sample of 1,020 images from the 51 university accounts (Table 3 ), the most common types posted were,humanizing images (31.0\%), showcasing images (28.8\%), and orienting images (14.3\%). Overall, 26 out of the 51 universities posted more humanizing images than any other type.

Table 3. Content analysis of image types for 1020 random images from 51 UK university Instagram accounts

\begin{tabular}{|l|c|c|}
\hline \multicolumn{1}{|c|}{ Type of image } & No. of images & Percentage \\
\hline 1. Orienting & 146 & $14.3 \%$ \\
\hline 2. Humanizing & 316 & $31.0 \%$ \\
\hline 3. Interacting & 58 & $5.7 \%$ \\
\hline 4. Placemaking & 130 & $12.8 \%$ \\
\hline 5. Showcasing & 294 & $28.8 \%$ \\
\hline 6. Crowdsourcing & 76 & $7.5 \%$ \\
\hline
\end{tabular}

Figure 5 gives an example image from each of the three most popular image categories.
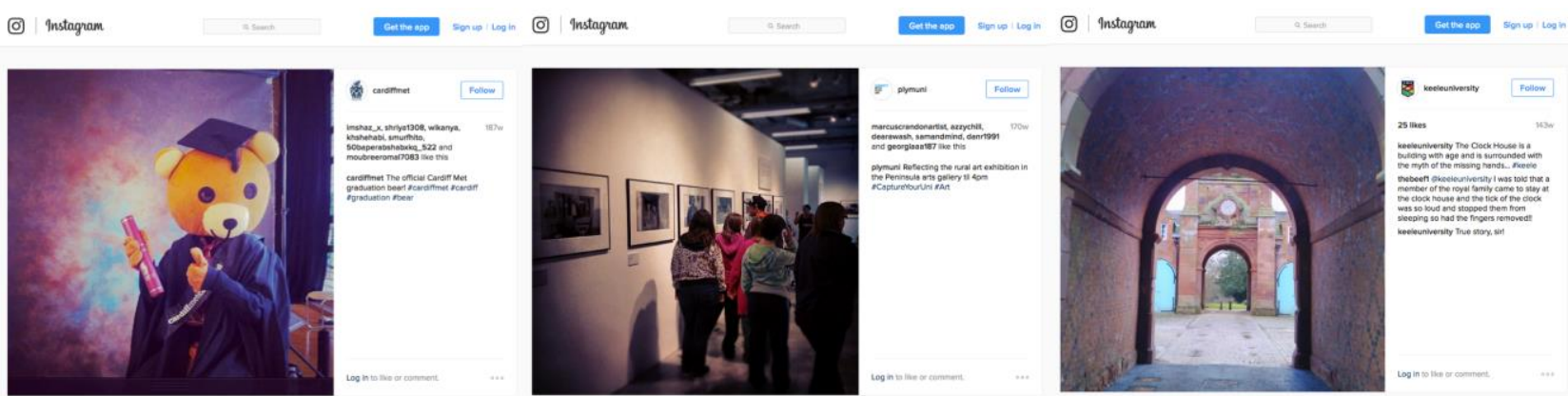

Figure 5. Examples of images from the three most popular image types: humanizing (left), showcasing (middle), orienting (right). (Images reproduced under copyright fair use).

\section{Successful presence on Instagram vs. types of image posted}

The modal number of likes for images was 2 , with a mean of 39 , and a median of 17 . The number of comments per image was also highly skewed, with a mode of 0 , and a maximum of 20 for a single image.

The multinominal logistic regression for the number of likes and comments, by image type, found an overall relationship between both the number of likes ( $p$ value 0.000 ) and the number of comments ( $p$ value 0.013 ) and image type. There was a statistically significant difference in the number of likes that orienting images received compared to the most popular category of image (humanizing), and for every 1 extra like that an image received, it was $2.8 \%$ more likely to be an orienting image.

There was also a statistically significant difference in the number of comments that crowdsourcing images received when compared to the most popular category of image (humanizing), and for every extra comment, an image was $3.1 \%$ more likely to be a crowdsourcing image.

\section{Successful presence on Instagram vs. other quantitative measures of Instagram behaviour}

There was a Spearman correlation of 0.431 for the relationship between the number of Instagram accounts an institution follows and the number of accounts they are followed by $(p<0.01)$. Thus, institutions following more accounts tended to have more followers (see Figure 6). The average (mean) number of followers per institution was 1,455 , and the average (mean) number of accounts that each institution followed was 90 . 


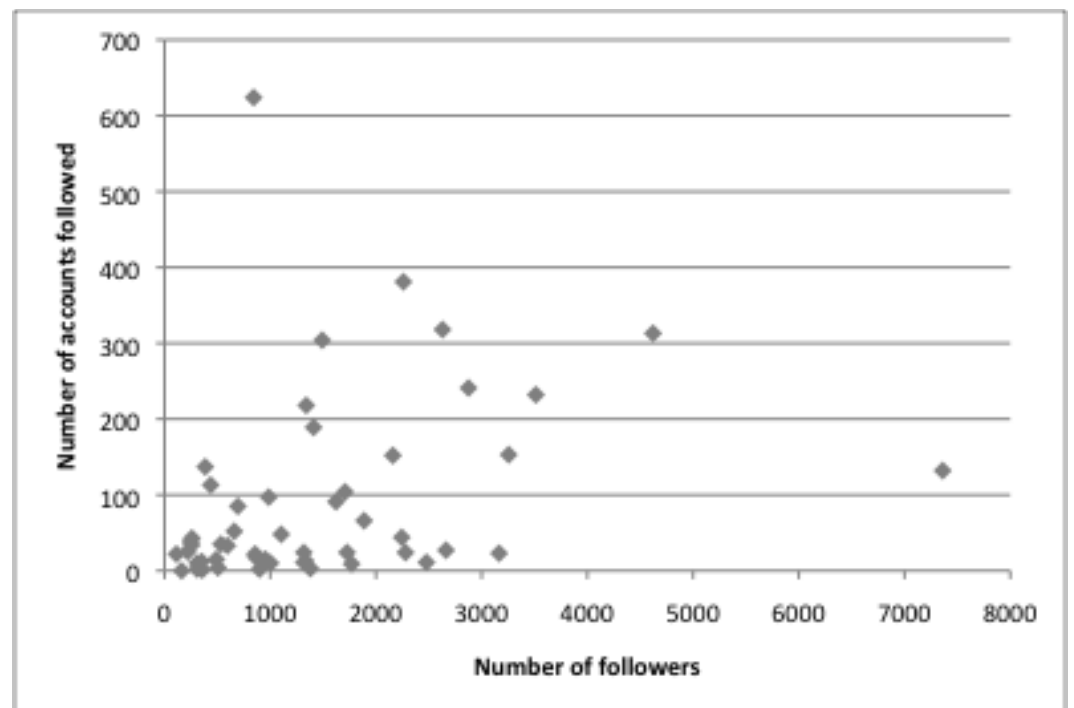

Figure 6. Followers vs number of accounts followed for 51 UK university Instagram accounts.

A Spearman correlation of $0.652(p<0.01)$ between the number of images that an institution posts and the number of followers that they have shows that the more images an institution posts, the more followers they tend to have (see Figure 7). The average number of images posted per institution was 223.

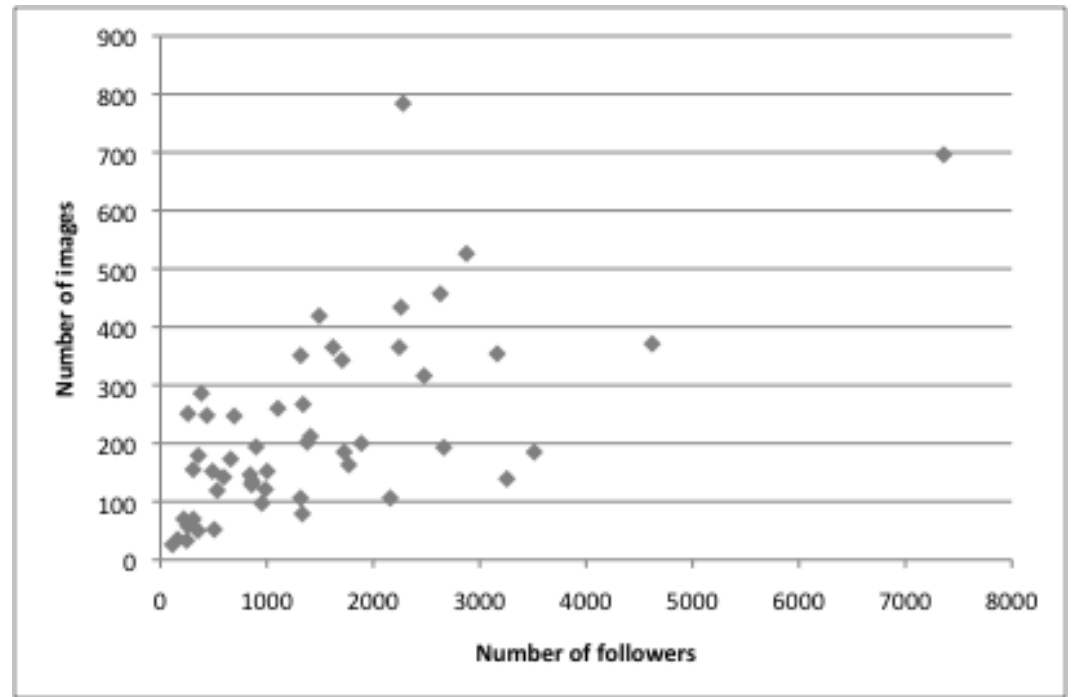

Figure 7. Followers vs number of images for 51 UK university Instagram accounts

\section{Discussion}

The results indicate that UK universities as a whole, at the time of data analysis for this investigation (Spring, 2015), had a limited presence on Instagram, with only 51 out of 128 institutions having a general Instagram account findable from the main homepage. However, from the literature review, university libraries can be proactive in implementing new social media services. Therefore, whilst general university Instagram accounts were not discovered for 77 of the institutions investigated, they might have had a specific library Instagram account, or subject department Instagram account for specific use within a teaching and learning setting. It seems likely that these more specific Instagram accounts are filling the gap in terms of UK universities' presences on Instagram. However, the motivation behind a specific account is likely to be very different to that of a general account, with library accounts being used to engage with current students, and subject department accounts being used for teaching and learning. For those institutions that do have a general Instagram account, they are not particularly well used, with an image only being posted on average every 3-4 days and the accounts not having many followers. The average number of followers per institution was 1,455 , despite most universities having tens of thousands of students (in addition to staff, alumni, and prospective students).

Most of the 51 institutions identified in this investigation had only been members of Instagram for an average of approximately 20 months (data for this investigation was collected in February 2015) and therefore the 
use of the Instagram is still in its infancy. Anderson (2015) similarly found a two-year time lag with libraries' adoption of the Tumblr service from when it was first launched. This time lag is compounded on Instagram by the fact that when it launched in 2010, it was an iPhone only service, and whilst it was opened up to Android devices in 2012, it is still nonetheless a mobile only service. This creates logistical limitations for organisations and academic institutions compared to individuals (i.e., are staff members who are responsible for posting images to Instagram issued with a specific 'work' mobile/tablet in order to post images, or are they expected to use their own mobile/tablet devices?). These logistical decisions contrast with those posed by a service such as Twitter, which is both mobile and web-based. This duality makes it much easier for designated staff members to login to Twitter on their work computers and post content.

In this investigation, humanizing images were found to be the most popular type of image posted by university accounts on Instagram (31.0\%) and in many ways this is no surprise. The primary focus of a humanizing image is to portray an element of warmth/humour/or amusement, and so it is unsurprising that this would be a popular type of image, especially in terms of marketing and branding, as universities are likely to want to present themselves in the most favourable light to prospective staff and students. Typical examples of humanizing images included: pictures of university mascots and logos (e.g., an image of a university logo cut into a pumpkin at Halloween time); pictures of 'friendly' staff and students at various events (e.g., an image of a lecturer giving an arm gesture to the camera at an open day as if beckoning new students to come to that particular university); and images of sunsets, rainbows, and nature shots from around campus; image content that tends to elicit positive sentiment.

The modal number of likes that images tended to receive was only 2 , despite the average number of followers per institution being 1,455 . However, there was a statistically significant difference in the number of likes that orienting images received when compared to the most popular category of image (humanizing). The fact that orienting images received more likes may be because they contain clearly defined locations that followers can relate to and recognise, and they are therefore perhaps more likely to 'like' images where the content is familiar and where followers feel an affiliation or connection to in some way.

Most images attracted no comments and so they do not seem to initiate much discussion or interaction. This is in contrast to the findings of Moritz (2012), Abbott et al. (2013), and Salomon (2013). However, no attempt was made in this investigation to assess to what level the university accounts were actively engaging with their followers, and it could be that followers were less inclined to engage with posts as the university accounts themselves were not particularly engaged with their followers. This lack of comments can also be attributed to the fact that a university Instagram account is obviously an 'organisation', rather than someone that a follower has an offline connection with such as a friend. This may dissuade followers from feeling comfortable enough to comment on images. However, there was a statistically significant difference in the number of comments that crowdsourcing images received when compared to the most popular category of image (humanizing). This finding can be attributed to the nature of crowdsourcing images, and the fact that they are posted with the primary intention of generating feedback, interaction, and engagement from viewers/followers. This finding agrees with the work of Vries, Gensler and Leeflang (2012), who also found that images that are interactive in nature tended to have more comments. An example of a crowdsourcing image in this investigation that received 12 comments was a photograph of a street scene with the accompanying caption 'which city were we visiting last week?' This kind of post obviously elicits comments from viewers in the form of people trying to guess the city correctly first. These social media metrics are imperfect as success indicators but it would be difficult to attribute any increase in the number of students enrolled at the university due to the success of the university's social media campaign, especially as universities would tend to have a number of different social media services that they are utilising at any one time.

The more accounts an institution followed, the more followers they were likely to have, however this was a weak correlation with a Spearman correlation of only .431. The split between accounts followed and followers was also very uneven, with the average number of followers being 1,455 , and the average number of accounts an institution followed being only 90 . This uneven split reflects the asymmetric network of Instagram as highlighted by Hu, Manikonda, and Kambhampati (2014). It also indicates that there is perhaps only a surface level of engagement with users, whereby an institution may only follow accounts that actively engage with the institution via either liking or commenting on images, rather than the institution reciprocally following all accounts that follow them. Institutions are also unlikely to proactively seek out engagement with followers by either commenting on or liking the images of accounts they do follow, or by seeking out new accounts to follow.

The more images an institution posts, the more followers they tend to have $(p<0.01)$.. The average number of images posted per institution was only 223 (most institutions had been a member of Instagram for an average of approximately 20 months), which equates to an average of one image posted every 2-3 days. 
This conservatism could be due to the logistics of posting images to a mobile only app compared to a webbased service, whereby perhaps only one member of dedicated staff is responsible for posting images, compared to a web-based service. Salomon (2013) advocates that posting one carefully-crafted good quality image per day is one of the keys to success on Instagram. Abbott et al. (2013) define good quality images on Instagram as those that: conform to the general rules of photography; are relatable to the viewer; and are of recognisable people.

A limitation of this study is that only 20 images per institution were analysed, which is a small sample and therefore the insights obtained into the online presence of UK universities on Instagram have to be treated with caution.

\section{Managerial implications}

It is important that heads of marketing, online content creators, social media campaign managers, and anyone who is responsible for the marketing, branding, and promoting of a university's services is aware of the significant role that social media plays in communicating with both current and prospective staff and students. If academic institutions are to create a successful presence on Instagram, then they need to post content more frequently and consistently, post good quality images, and build reciprocal relationships with their followers in order to increase engagement and interaction. Although humanizing images are the most commonly posted, the results suggest that crowdsourcing and orienting images are more important for generating interactions with followers and so universities should consider posting more of them.

\section{Conclusions}

This investigation gives a first insight into the online presence of UK universities on Instagram. At the time of data analysis for this investigation (Spring, 2015), UK universities had a limited presence on Instagram for general university accounts. Less than half of the UK universities identified in this investigation had a general Instagram account that was displayed on their main web pages. Most universities with a general Instagram account had only been using it since 2013 and so their usage policies may not have matured yet.

Universities with a general Instagram account are not fully using it to engage with current or prospective students. Institutions posted images only every 2-3 days, and did not reciprocate with accounts that followed them. This suggests that academic institutions are missing the opportunity to actively engage with their followers. Following others is not enough to trigger engagement (Jang, Han, \& Lee, 2015) and so more indepth strategies should also be followed.

Since Instagram was one of the fastest growing social media services at the time of writing, academic institutions must use it more effectively if they are to engage with tech-savvy students in new and innovative ways and to market themselves successfully to prospective staff and students.

Avenues for future research include:

- A qualitative investigation of a limited number of universities to assess how they engage with their followers in more detail.

- A cluster analysis to cluster institutions according to type (e.g., Russell Group, pre- and post- 1992 universities etc.) and country, to see if different types of universities have different image posting practices.

- A cluster analysis to cluster institutions according to the types of accounts they follow.

- Content analyses to investigate how universities are placing images in other social media services, such as Twitter and Pinterest.

- Extensions of the content analysis scheme to make it suitable for researching image use in different organisations and different contexts.

\section{References}

Abbott, W., Donaghey, J., Hare, J., \& Hopkins, P.J. (2013), "An Instagram is worth a thousand words: An industry panel and audience Q \& A", Library Hi Tech News, Vol. 30 No. 7, pp. 1-6.

Anderson, K. E. (2015), "Getting acquainted with social network apps: Tumblin' through the visual web", Library Hi Tech News, Vol. 32 No. 7, pp. 8-11.

Angus, E., Stuart, D., \& Thelwall, M. (2010), "Flickr's potential as an academic image resource: an exploratory study", Journal of Librarianship and Information Science, Vol. 42 No. 4, pp. 268-278. 
BBC News Technology. (2012), "Facebook buys Instagram photo sharing network for \$1bn", 10 April 2012, available at: http://www.bbc.co.uk/news/technology-17658264 (accessed 19 July 2015).

Chapleo, C. (2011), "Exploring rationales for branding a university: Should we be seeking to measure branding in UK universities?" Journal of Brand Management, Vol. 18 No. 6, pp. 411-422.

Coelho, R.L.F., Oliveira, D.S.D., and Almeida, M.I.S.D. (2016), "Does social media matter for post typology? Impact of post content on Facebook and Instagram metrics", Online Information Review, Vol. 40 No. 4, pp. 458-471.

comScore (2013), "US digital future in focus", comScore.com, available at: www.comscore.com/Insights/Presentations-and-Whitepapers/2013/2013-US-Digital-Future-in-Focus (accessed 16 November 2015).

Economist Intelligence Unit (EIU) (2007), "Beyond loyalty: meeting the challenge of customer engagement, part 2", 2007, available at:

http://graphics.eiu.com/files/ad_pdfs/eiu_AdobeEngagementPt_II_wp.pdf (accessed 28 December 2016).

Ferrara, E., Interdonato, R., and Tagarelli, A. (2014), "Online popularity and topical interests through the lens of instagram", In Proceedings of the 25th ACM conference on Hypertext and social media, September, ACM, pp. 24-34.

Guidry, J., Messner, M., Jin, Y., and Medina-Messner, V. (2014), "From \#mcdonaldsfail to \#dominossucks: An analysis of Instagram images about the 10 largest fast food companies", Paper presented at the 17th International Public Relations Research Conference, Holiday Inn University of Miami, Coral Gables, Florida, March 5-9, 2014.

Hansen, K. Nowlan, G. and Winter, C. (2012), "Pinterest as a tool: applications in academic libraries and higher education", Partnership: The Canadian journal of library and information practice and research, Vol. 7 No. 2.

Hochman, N. and Manovich, L. (2013), "Zooming into an Instagram City: Reading the local through social media", First Monday, 18(7).

Hu, Y., Manikonda, L., and Kambhampati, S. (2014), "What we instagram: A first analysis of instagram photo content and user types", Proceedings of ICWSM. AAAI.

Ibrahim, Y. (2015), "Instagramming life: banal imaging and the poetics of the everyday", Journal of Media Practice, Vol. 16 No. 1, pp. 42-54.

Instagram (2015), “Creating a community of 400 million", Instagram blog, September 22nd 2015, available at: http://blog.instagram.com/post/129662501137/150922-400million (accessed 18 November 2015).

Jang, J. Y., Han, K., and Lee, D. (2015). "No reciprocity in liking photos: analyzing like activities in Instagram". In Proceedings of the 26th ACM Conference on Hypertext \& Social Media (pp. 273-282). New York, NY: ACM Press.

Kharpal, A. (2015), "Facebook's Instagram hits 400M users, beats Twitter", CNBC, available at: http://www.cnbc.com/2015/09/23/instagram-hits-400-million-users-beating-twitter.html (accessed 18 November 2015).

Kiang, M.Y., Raghu, T.S. and Shang, K.H.M., (2000), "Marketing on the Internet-who can benefit from an online marketing approach?”, Decision Support Systems, Vol. 27 No. 4, pp. 383-393.

Kietzmann, J. H., Hermkens, K., McCarthy, I. P., and Silvestre, B. S. (2011), "Social media? Get serious! Understanding the functional building blocks of social media", Business horizons, Vol. 54 No. 3, pp. 241251.

Kittle, B., Ciba, D. (1999), "Relationship marketing in higher education via the World Wide Web: a study of home pages examining student retention strategies", Proceedings of the 1999 Symposium for the Marketing of Higher Education, American Marketing Association, Chicago, pp. 165-175 
Klassen, M. and Sitzman, E. (2000), "At the intersection of demand creation and demand fulfillment: Which schools are getting there first and why", Journal of Marketing for Higher Education, Vol. 10 No. 1, pp. 43-53.

Krippendorf, K. (2004), Content Analysis: An Introduction to its Methodology, Sage Publications, USA.

McNely, B. (2012), "Shaping organizational image-power through images: Case histories of Instagram", Proceedings of the IEEE International Professional Communication Conference, IEEE, Piscataway, NJ.

Moran, M., Seaman, J. and Tinti-Kane, H. (2011), "Teaching, learning, and sharing: How today's higher education faculty use social media", Babson Survey Research Group, available at: http://files.eric.ed.gov/fulltext/ED535130.pdf (accessed 19 July 2015).

Moritz, D. (2012), "The Shift to Visual Social Media - 6 tips for Business", Socially Sorted, December 15th 2012, available at: http://sociallysorted.com.au/?s=the+shift\&submit=Search (accessed: 4 August 2015).

Parr, C. (2014), "Top 100 most influential UK and US universities on Twitter”, Times Higher Education, available at: https://www.timeshighereducation.co.uk/news/top-100-most-influential-uk-and-us-universitieson-twitter/2013373.article (accessed 19 July 2015).

Rainie, L., Brenner, J. and Purcell, K. (2012), "Photos and Videos as Social Currency Online", PewResearch Internet Project, September $13^{\text {th }}$ 2012, available at: http://www.pewinternet.org/2012/09/13/photos-and-videos-as-social-currency-online/ (accessed 24 July 2015).

Richards, R. (2016), "How many people use social media?", Sysomos, April $21^{\text {st }} 2016$, available at: https://blog.sysomos.com/2016/04/21/how-many-people-use-social-media/ (accessed 14 December 2016).

Rolfe, H. (2003), "University strategy in an age of uncertainty: the effect of higher education funding on old and new universities", Higher Education Quarterly, Vol. 57 No. 1, pp. 24-47.

Roper, S. and Davies, G. (2007), "The corporate brand: Dealing with multiple stakeholders", Journal of Marketing Management, Vol. 23 No. 1-2, pp. 75-90.

Rose, G. (2012). Visual methodologies: An introduction to researching with visual materials. London: Sage.

Salomon, D. (2013), "Moving on from Facebook: Using Instagram to connect with undergraduates and engage in teaching and learning", College \& Research Libraries News, Vol. 74 No. 8, pp. 408-412.

Saichaie, K. and Morphew, C.C. (2014). "What college and university websites reveal about the purposes of higher education", The Journal of Higher Education, Vol. 85 No. 4, pp. 499-530.

Stamp, R. (2004), "The new challenge of branding buy-in", Education News, 7.

Thelwall, M., Goriunova, O. Vis, F., Faulkner, S., Burns, A., Aulich, J. Mas-Bleda, A., Stuart, E. \& D'Orazio, F. (2016), "Chatting through pictures? A classification of images tweeted in one week in the UK and USA", Journal of the Association for Information Science and Technology, Vol. 67 No. 11, pp. 2575-2586.

Tweney, D. (2015), "Engagement to die for: Snapchat has $100 \mathrm{M}$ daily users, $65 \%$ of whom upload photos", May $26^{\text {th }} 2015$, available at: http://venturebeat.com/2015/05/26/snapchat-has-100m-daily-users-65-of-whomupload-photos/ (accessed 2 February 2016).

Van House, N.A. and Davis, M. (2005), "The social life of cameraphone images", In Proceedings of the Pervasive Image Capture and Sharing: New Social Practices and Implications for Technology Workshop (PICS 2005) at the Seventh International Conference on Ubiquitous Computing (UBICOMP), (September 11-14, 2005, Tokyo, Japan).

Vong, K. (2012), "Image is Everything: Why People Are Hooked on Image-Based Social Media", TrendReports, August $13^{\text {th }}$ 2012, available at: http://www.trendreports.com/article/imagebased-social-media (accessed 18 November 2015).

De Vries, L., Gensler, S. and Leeflang, P.S. (2012), "Popularity of brand posts on brand fan pages: An investigation of the effects of social media marketing", Journal of Interactive Marketing, Vol. 26 No. 2, pp. 83-91. 